\title{
TGF- $\beta$ and cancer: Is Smad3 a repressor of hTERT gene?
}

\author{
He $\mathrm{Li}^{1}$, Dakang $\mathrm{Xu}^{1}$, Ban-Hock Toh ${ }^{1}$, Jun-Ping Liu ${ }^{1}$ \\ ${ }^{1}$ Department of Immunology, Molecular Signaling Laboratory, Monash University, Melbourne, Australia
}

Transforming growth factor $\beta$ (TGF- $\beta$ ) carries out tumor suppressor activity in epithelial and lymphoid cells, whereas telomerase is required for most cancers. Although the molecular mechanisms by which TGF- $\beta$ acts as a tumor suppressor are yet to be fully established, a link between TGFb and its tumor suppressor activity by telomerase has been suggested. Recently, we have noted a novel mode of action for TGF- $\beta$ through which human telomerase reverse transcriptase (hTERT) gene is repressed in immortal and neoplastic cells, confirming that one of the mechanisms underlying TGF- $\beta$ suppression of tumor growth may be through inhibiting hTERT gene transcription. Moreover, the inhibition of hTERT gene by TGF- $\beta$ suggests a cis action of the TGF- $\beta$ signaling molecule Smad3 on hTERT promoter directly. This article examines our current understanding and investigation of TGF- $\beta$ regulation of telomerase activity, and presents a model in which Smad3 participates in regulating hTERT gene transcription by acting as a repressor directly. Engineering the interface between Smad3 and hTERT gene may lead to a new strategy to inhibit telomerase activity in cancer.

Cell Research (2006) 16:169-173. doi:10.1038/sj.cr.7310023; published online 13 February 2006

Keywords: telomerase, TERT, gene expression, Smad3, TGF- $\beta$, cancer

\section{Introduction}

The TGF- $\beta$ superfamily comprises three TGF- $\beta$ isoforms (TGF- $\beta$ 1-3), and other cytokines involved in cell differentiation and proliferation that include the bone morphogenetic proteins (BMP), inhibins and activins. TGF- $\beta$ has both inhibitory and stimulatory effects on cell proliferation, acting as a tumour suppressor and oncogene. In normal development, TGF- $\beta$ promotes cell differentiation and inhibits proliferation, whereas during tumorigenesis TGF- $\beta$ secreted from tumour cells often loses its inhibitory function in favour of its oncogenic activity [1]. The mechanisms of actions of TGF- $\beta$ have not yet been fully understood, so investigation of TGF- $\beta$ intracellular signaling events provides insight into normal cellular functions and abnormal effects of TGF- $\beta$ in normal cell development, physiology and tumour formation.

\section{TGF- $\beta$ signaling}

A heterotetrameric complex of two trans-membrane

Correspondence: $\mathrm{He} \mathrm{Li}$

Department of Immunology, Monash Medical School, AMREP, Commercial Road, Prahran, Victoria 3181, Australia.

Tel.: 61-3-99030715; Fax: 61-3-99030018;

E-mail: he.li@med.monash.edu.au receptor serine/threonine kinases mediates TGF- $\beta$ signalling. The receptor complex consists of a ligand binding type II receptor (TRII) and a signalling type I receptor (TRI) [2]. Smad proteins 1-8 are downstream effectors of TGF- $\beta$ signalling, with Smad 1, 2, 3, 5 and 8 binding to TRI as R-Smads, Smad 4, a common intermediate Smad or C-Smad that binds R-Smad, and Smad 6 and 7, inhibitory Smads. Smad3 specifically mediates TGF- $\beta$ action, whereas Smads 1, 2, 5 and 8 often mediate actions of other members of the TGF- $\beta$ superfamily. Upon phosphorylation and activation by TRII, TRI recruits and phosphorylates RSmads, and once phosphorylated, R-Smads form signalling heterodimers or heterotrimers with Smad4 to translocate into the nucleus to regulate gene expression.

With profound anti-proliferative effects on a variety of cell types, including several types of tumor cells $[3,4]$, the anti-proliferative effects of TGF- $\beta$ have been reported to be primarily mediated through the up-regulation of cell cycle inhibitors such as $\mathrm{p} 15^{\mathrm{INK} 4 \mathrm{~b}}$ and $\mathrm{p} 21^{\mathrm{CIP} 1}$, and down-regulation of cell cycle stimulators such as c-myc and cyclin-dependent kinases 4 and 6 (Figure 1). Concomitantly TGF- $\beta$ may up-regulate the cyclin-dependent kinase inhibitors $\mathrm{p} 15^{\mathrm{INK} 4 \mathrm{~b}}$ and $\mathrm{p} 21^{\mathrm{CIP} 1}$ by both Smad directed transcriptional activation and indirect release of repression by c-myc. TGF- $\beta$ also signals through other pathways such as mitogen activated protein kinase (MAPK) and protein phosphatase 2A 


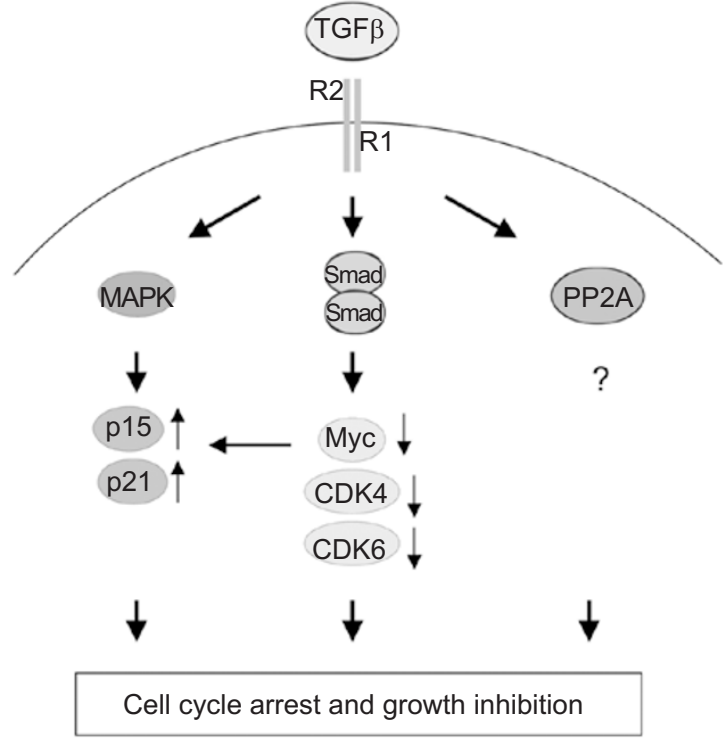

Figure 1 Schematic presentation of mechanisms that have been shown to mediate TGF $\beta$ regulation of cell cycle arrest and growth inhibition.

(PP2A), although the molecular details are unclear $[3,5,6]$. In immortalized keratinocyte cell line $(\mathrm{HaCaT})$ and several other cell types, TGF $\beta$-induction of $\mathrm{p} 15^{\mathrm{INK} 4 \mathrm{~b}}$ and $\mathrm{p} 21^{\mathrm{CIP1}}$ has been shown to be through Smad-independent activation of the MAPK pathway, and the PP2A pathway can also mediate Smad-independent growth inhibition [6].

\section{Telomeres and telomerase}

Human telomeres are the nucleoprotein complex of chromosome ends, consisting of up to three thousand TTAGGG repeat sequences and associated proteins. Interestingly, telomeres form protective caps on chromosome ends for genomic integrity and stability that are important for continuous proliferation including cancer [7, 8]. Owing to the 'end replication problem', telomeres shorten progressively with each round of cell division, and subsequently, cells are triggered to enter a permanent growth arrest stage named 'replicative senescence' when their telomeres reach a critical size that elicits the DNA damage checkpoint response or p53 and $\mathrm{Rb}$ activation $[8,9]$. It is suggested that the replicative senescence programmed by telomere attritions act as a potent barrier to cancer development.

Telomeric DNA is synthesized by telomerase, a RNAdependent DNA polymerase that is generally silent in normal human somatic cells due to stringent repression of the human telomerase reverse transcriptase (hTERT) gene encoding the catalytic component of telomerase $[8,10,11]$. Expression of hTERT stimulates cell proliferation toward immortality [12-16] and contributes to tumor formation [17,
18]. In contrast, inhibition of telomerase results in erosion of telomeres, compromise of growth capacity and apoptosis of highly proliferative cells [19-24]. Thus, hTERT is essentially a key element in telomerase activation, telomere maintenance and tumor development, and is proposed as a promising target for anticancer therapy.

Repressed in association with a gradual loss of proliferative potential and gain of differentiation of mature cells, the exact role and mechanisms of hTERT repression in cell differentiation remains to be established [25-28]. Transcriptional activation of the hTERT gene is a critical, initial rate-limiting step in telomerase activation in human cancers. The hTERT gene promoter provides a platform with a number of binding sites for transcriptional regulation, including two typical E-boxes and several GCboxes for the transcription factors c-myc/Max and Sp1, respectively [29-31]. Expression of c-myc rapidly induces hTERT gene transcription [32], with the binding of c-myc to the E-box being coupled to cell proliferation and that is disengaged by Mad1 during differentiation [33]. Another E box binding protein called upstream stimulatory factor (USF) also up-regulates hTERT promoter activity. USF is inhibited by the N-terminal truncated form USF2 acting as an inhibitory competitor that is increased in telomerase negative cells [34].

However, little is known of the mechanisms by which hTERT gene is repressed both during normal tissue development and ageing related tumorigenesis. Several approaches have been investigated in order to repress telomerase during tumor development and metastasis; these include using RNA interference technology and antisense oligonucleotides to target against the template region of the RNA component hTR or against reverse transcriptase hTERT, the use of reverse transcriptase inhibitors to inhibit hTERT catalytic activity, and agents that promote or stabilize G-quadruplex formation in telomeric DNA [35-37]. In addition, we recently identified a synthetic peptide that inhibits telomerase activity in vitro and in vivo (unpublished). We also investigated the significance of TGF- $\beta$ inhibition of telomerase activity and hTERT gene expression, and the mechanisms by which TGF- $\beta$ inhibits through the signaling protein Smad3 to repress hTERT gene directly.

\section{TGF- $\beta$ regulation of telomerase activity}

Among different hormones and growth factors, TGF- $\beta$ appears to be the only potent inhibitory growth factor that inhibits telomerase in cell cultures under physiologically relevant conditions [38]. The levels of TGF- $\beta$ are inversely correlated with the levels of telomerase activity [5]. Treatment of human lung adenocarcinoma A549 cells with TGF- $\beta$ results in complete abrogation of telomerase activity in a prolong time course of 30 days [4]. Interruption of TGF- $\beta$ 
autocrine action in human breast cancer MCF-7 cells increases telomerase activity, whereas restoration of autocrine TGF- $\beta$ activity in human colon carcinoma HCT116 cells significantly inhibits telomerase activity [5]. The findings that inhibition of telomerase activity by TGF- $\beta$ correlates with decreased hTERT mRNA levels suggest that inhibition occurs through transcriptional silencing of the hTERT promoter $[4,5]$.

While the mechanism(s) underlying hTERT gene repression induced by TGF- $\beta$ remains unclear, it is possible that the repression is at least in part to be mediated by TGF- $\beta$ suppression of c-myc proto-oncogene that is a hTERT transcription factor [5]. Firstly, the tumour suppressor activity of TGF- $\beta$ in the epithelial and lymphoid cells from which most human cancers arise is thought to be largely due to transcriptional inhibition of the proto-oncogene c-myc, and secondly, the repression results from binding of a Smad 3 complex to a TGF- $\beta$ inhibitory element in the c-myc promoter [39]. Thus, TGF- $\beta$ induced hTERT gene repression may involve a trans action of $\mathrm{Smad} 3$ repression of c-myc, thereby inhibiting c-myc transcriptional activation of hTERT gene.

To establish the mechanisms by which TGF- $\beta$ regulates telomerase, we have recently characterized the actions of TGF- $\beta$ and investigated the signaling pathways downstream of TGF- $\beta$, and found a rapid repression of telomerase activity by TGF- $\beta$.

We noted that TGF- $\beta$ down regulated telomerase activity in 2-4 h in human breast cancer MCF-7 cells. Rapid down-regulation of telomerase activity also occurred in muscular smooth muscle cells and in renal epithelial cells, suggesting an early inhibitory mechanism in preventing cell proliferation. In contrast, relatively delayed mechanism after $12 \mathrm{~h}$ of TGF- $\beta$ inhibition of telomerase implicates multiple intracellular mechanisms mediating TGF- $\beta$-induced telomerase inhibition. The rapid inhibitory effect on telomerase of TGF- $\beta$ may constitute a novel cmyc transcription-independent mechanism through which TGF- $\beta$ operates to elicit tumour suppressor activity. We hypothesize that TGF- $\beta$ signal transducer Smad protein(s) might be involved in direct $c i s$ regulation of hTERT gene transcription by acting at the hTERT gene promoter, responsible for the rapid suppression of telomerase activity induced by TGF- $\beta$.

\section{Identification of $\mathrm{Smad} 3$ as a repressor of hTERT}

Transcription of the hTERT gene is the first key step in telomerase activation (Figure 2), and the proto-oncogene c-myc interacts with the hTERT gene promoter resulting in hTERT transcription [40]. To test the hypothesis that inhibitory Smad3 protein might be involved in negative regulation of hTERT gene transcription directly, indepen-

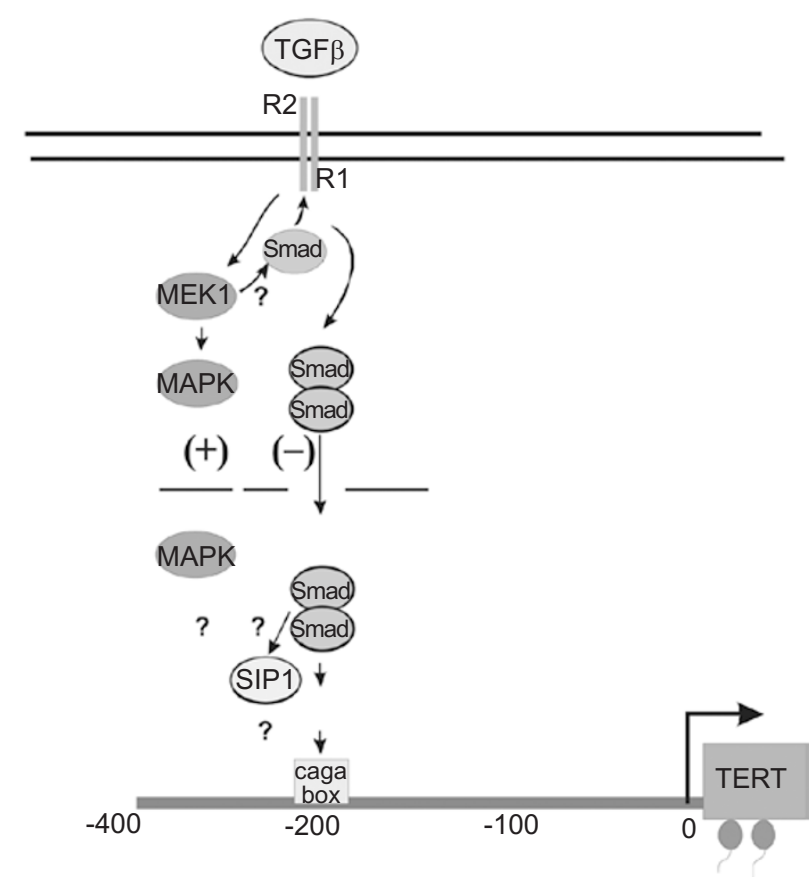

Figure 2 Pathways of transcription regulations of hTERT gene by TGF $\beta$. The promoter of hTERT gene consists of various binding sites for transcription factors and repressors. Phosphorylated and activated by TGF $\beta$ signaling, Smad3 migrates into the nucleus and acts at the hTERT gene promoter directly in silencing hTERT gene transcription. Roles of MAP kinase and SIP1 implicated in TGF $\beta$ signaling and regulation of hTERT may be involved in regulating the action of Smad3, which requires further investigation.

dent of c-myc, we manipulated intracellular Smad3 gene expression and determined its effect on hTERT gene expression. For the first time we noted that Smad3 interacted with a specific site of the hTERT promoter in response to TGF- $\beta$ stimulation, which led to a significant inhibition of hTERT gene transcription. Thus, Smad3 may constitute a negative regulatory system to balance c-myc transcriptional activation of hTERT gene in response to extracellular signals of TGF- $\beta$ in the regulation of telomerase activity and cell proliferation.

Since previous studies have shown that c-myc repression may be involved in telomerase inhibition induced by TGF- $\beta$ [41] and that SIP1 is a TGF- $\beta$ downstream element that mediates TGF- $\beta$ induced telomerase inhibition [42], it is possible that the relatively rapid inhibition of telomerase activity is chiefly mediated by Smad3 repression of hTERT gene directly, whereas delayed inhibition mediated by transcription-dependent activation of SIP1 and repression of c-myc. The involvement of Smad3 directly repressing hTERT gene is supported by binding of Smad3 to the hTERT promoter DNA in vitro as demonstrated in gel electrophoresis mobility shift assay and in intact cells as 


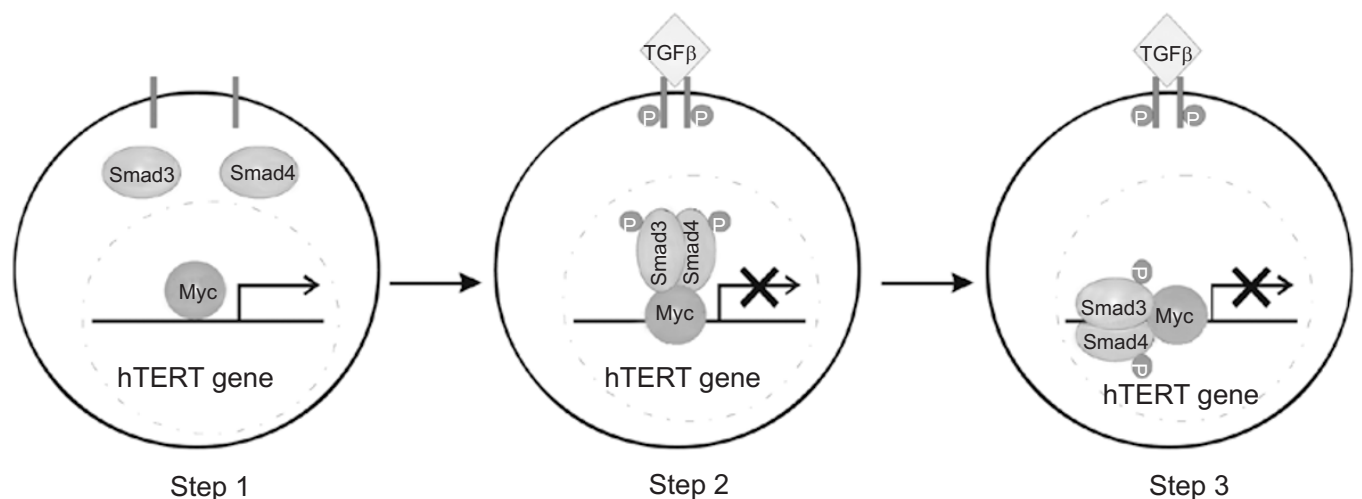

Figure 3 Working model of Smad3 interaction with c-myc and hTERT gene promoter DNA. In the absence of TGF- $\beta$ signaling (step $1)$, Smad3 stays in cytoplasm without being phosphorylated, and hTERT gene is driven for transcription by c-myc. TGF- $\beta$ stimulation results in Smad3 phosphorylation, nuclear entry and binding to c-myc leading to hTERT gene inactivation (step 2). Interacting with c-myc and/or hTERT gene directly, Smad3 is recruited to bind the hTERT gene promoter DNA resulting in further repression of the hTERT gene (step 3).

demonstrated by chromatin immunoprecipitation. Analysis of hTERT gene promoter also reveals multiple putative binding sites for Smad3, and mutations of these sites individually suggest a CAGA box in the vicinity of a myc binding E-box to mediate the TGF- $\beta$ - or Smad3-induced hTERT gene promoter activity.

Further investigations are required to delineate characteristics of Smad3 molecular interactions at hTERT gene promoter. Given that the Smad3 binding site CAGA box is adjacent to the E-box of c-myc binding site, it cannot be excluded that Smad3 binding to the CAGA box of hTERT promoter has no effect on c-myc actions in gene transcriptional activation of hTERT. Indeed, previous studies have shown that Smad3 undergoes protein-protein interaction directly with c-myc [43]. Thus, a working model is proposed that Smad3 interacts with both c-myc protein and hTERT gene promoter DNA (Figure 3). The potential interactions recruits Smad3 onto the already activated hTERT gene promoter by c-myc. Binding to c-myc itself might impact upon c-myc transcriptional effect on hTERT gene. Thus, two modes of repression of hTERT gene by Smad3 may include interactions with c-myc and with hTERT gene promoter DNA. Molecular engineering of the interactions would lead to novel strategies in targeting hTERT gene expression and telomerase activity in cancer.

\section{Conclusion and Prospect}

In summary, TGF- $\beta$ operates with tumor suppressor activity in epithelial and lymphoid cells, which may be in part mediated by repression of telomerase activity that is required for most cancers. We show a novel mode of action for TGF- $\beta$ through which Smad3 carries out a rapid hTERT gene repressor activity in immortal and neoplastic cells. Further studies are required to elucidate roles of TGF- $\beta$, and Smad3 intracellular signaling in telomere homeostasis during stem cell development and tumorigenesis. Studies to engineer the interface between Smad3 and hTERT gene may lead to new information in anti-cancer therapeutic strategy by targeting telomerase gene expression and cancer cell immortalization.

\section{Acknowledgements}

This work was supported by grants from the Australia Research Council (grant numbers: DP0449967 and DP0664192 to JPL) and National Health \& Medical Research Council of Australia (grant No. 384189 to JPL).

\section{References}

1 Siegel PM, Massague J. Cytostatic and apoptotic actions of TGF- $\beta$ eta in homeostasis and cancer. Nat Rev Cancer 2003; 3:807-21.

2 Fanayan S, Firth SM, Baxter RC. Signaling through the Smad pathway by insulin-like growth factor-binding protein-3 in breast cancer cells. Relationship to transforming growth factor-beta 1 signaling. J Biol Chem 2002; 277:7255-61.

3 Roberts AB, Russo A, Felici A, Flanders KC. Smad3: a key player in pathogenetic mechanisms dependent on TGF-ßeta. Ann N Y Acad Sci 2003; 995:1-10.

4 Katakura Y, Nakata E, Miura T, Shirahata S. Transforming growth factor beta triggers two independent-senescence programs in cancer cells. Biochem Biophys Res Commun 1999; 255:110-5.

5 Yang H, Kyo S, Takatura M, Sun L. Autocrine transforming growth factor beta suppresses telomerase activity and transcription of human telomerase reverse transcriptase in human cancer 
cells. Cell Growth Differ 2001; 12:119-27.

6 Derynck R, Zhang YE. Smad-dependent and Smad-independent pathways in TGF-beta family signalling. Nature 2003; 425:577-84.

7 Hackett JA, Greider CW. Balancing instability: dual roles for telomerase and telomere dysfunction in tumorigenesis. Oncogene 2002; 21:619-26.

8 Hahn WC. Telomere and telomerase dynamics in human cells. Curr Mol Med 2005; 5:227-31.

9 Chang S, Khoo C, DePinho RA. Modeling chromosomal instability and epithelial carcinogenesis in the telomerase-deficient mouse. Semin Cancer Biol 2001; 11:227-39.

10 Blackburn EH. Telomeres and telomerase: their mechanisms of action and the effects of altering their functions. FEBS Lett 2005; 579:859-62.

11 Blasco MA. Telomeres and human disease: ageing, cancer and beyond. Nat Rev Genet 2005; 6:611-22

12 Bodnar AG, Ouellette M, Frolkis M, et al. Extension of life-span by introduction of telomerase into normal human cells. Science 1998; 279:349-52.

13 Nakayama J, Tahara H, Tahara E, et al. Telomerase activation by hTRT in human normal fibroblasts and hepatocellular carcinomas. Nat Genet 1998; 18:65-8.

14 Vaziri H, Benchimol S. Reconstitution of telomerase activity in normal human cells leads to elongation of telomeres and extended replicative life span. Curr Biol 1998; 8:279-82.

15 Wen J, Cong YS, Bacchetti S. Reconstitution of wild-type or mutant telomerase activity in telomerase- negative immortal human cells. Hum Mol Genet 1998; 7:1137-41.

16 Counter CM, Hahn WC, Wei W, et al. Dissociation among in vitro telomerase activity, telomere maintenance, and cellular immortalization. Proc Natl Acad Sci U S A 1998; 95:14723-8.

17 Hahn WC, Counter CM, Lundberg AS, et al. Creation of human tumour cells with defined genetic elements. Nature 1999; 400:464-8.

18 Stewart SA, Hahn WC, O'Connor BF, et al. Telomerase contributes to tumorigenesis by a telomere length-independent mechanism. Proc Natl Acad Sci U S A 2002; 99:12606-11

19 Feng J, Funk WD, Wang SS, et al. The RNA component of human telomerase. Science 1995; 269:1236-41.

20 Lee HW, Blasco MA, Gottlieb GJ, et al. Essential role of mouse telomerase in highly proliferative organs. Nature 1998; 392:56974.

21 Kondo S, Tanaka Y, Kondo Y, et al. Antisense telomerase treatment: induction of two distinct pathways, apoptosis and differentiation. FASEB J 1998; 12:801-11.

22 Niida H, Matsumoto T, Satoh H, et al. Severe growth defect in mouse cells lacking the telomerase RNA component. Nat Genet 1998; 19:203-6.

23 Rudolph KL, Chang S, Lee HW, et al. Longevity, stress response, and cancer in aging telomerase-deficient mice. Cell 1999; 96:70112.

24 Hahn WC, Stewart SA, Brooks MW, et al. Inhibition of telomerase limits the growth of human cancer cells [see comments]. Nat Med 1999; 5:1164-70.

25 Armstrong L, Saretzki G, Peters H, et al. Overexpression of telomerase confers growth advantage, stress resistance, and enhanced differentiation of ESCs toward the hematopoietic lineage. Stem Cells 2005; 23:516-29.
26 Wang J, Feng H, Huang XQ, et al. Human telomerase reverse transcriptase immortalizes bovine lens epithelial cells and suppresses differentiation through regulation of the ERK signaling pathway. J Biol Chem 2005; 280:22776-87.

27 Lee MK, Hande MP, Sabapathy K. Ectopic mTERT expression in mouse embryonic stem cells does not affect differentiation but confers resistance to differentiation- and stress-induced p53dependent apoptosis. J Cell Sci 2005; 118:819-29.

28 Li H, Pinto AR, Duan W, et al. Telomerase down-regulation does not mediate PC12 pheochromocytoma cell differentiation induced by NGF, but requires MAP kinase signalling. J Neurochem 2005; 95:891-901.

29 Horikawa I, Cable PL, Mazur SJ, et al. Downstream E-boxmediated regulation of the human telomerase reverse transcriptase (hTERT) gene transcription: evidence for an endogenous mechanism of transcriptional repression. Mol Biol Cell 2002; 13:2585-97.

30 Li H, Liu JP. Signaling on telomerase: a master switch in cell aging and immortalization. Biogerontology 2002; 3:109-18.

31 Janknecht R. On the road to immortality: hTERT upregulation in cancer cells. FEBS Lett 2004; 564:9-13.

$32 \mathrm{Wu}$ KJ, Grandori C, Amacker M, et al. Direct activation of TERT transcription by c-MYC. Nat Genet 1999; 21:220-4.

$33 \mathrm{Xu}$ D, Popov N, Hou M, et al. Switch from Myc/Max to Mad1/ Max binding and decrease in histone acetylation at the telomerase reverse transcriptase promoter during differentiation of HL60 cells. Proc Natl Acad Sci U S A 2001; 98:3826-31.

34 Yago M, Ohki R, Hatakeyama S, et al. Variant forms of upstream stimulatory factors (USFs) control the promoter activity of hTERT, the human gene encoding the catalytic subunit of telomerase. FEBS Lett 2002; 520:40-6.

35 Li S, Rosenberg JE, Donjacour AA, et al. Rapid inhibition of cancer cell growth induced by lentiviral delivery and expression of mutant-template telomerase RNA and anti-telomerase shortinterfering RNA. Cancer Res 2004; 64:4833-40.

36 Marin VL, Roy S, Armitage BA. Recent advances in the development of peptide nucleic acid as a gene-targeted drug. Expert Opin Biol Ther 2004; 4:337-48.

37 Kelland LR. Overcoming the immortality of tumour cells by telomere and telomerase based cancer therapeutics - current status and future prospects. Eur J Cancer 2005; 41:971-9.

38 Bayne S, Liu JP. Hormones and growth factors regulate telomerase activity in ageing and cancer. Mol Cell Endocrinol 2005; 240:11-22.

39 Frederick JP, Liberati NT, Waddell DS, et al. Transforming growth factor beta-mediated transcriptional repression of c-myc is dependent on direct binding of Smad3 to a novel repressive Smad binding element. Mol Cell Biol 2004; 24:2546-59

40 Liu JP. Studies of the molecular mechanisms in the regulation of telomerase activity. FASEB J 1999; 13:2091-104.

41 Cerezo A, Kalthoff H, Schuermann M, et al. Dual regulation of telomerase activity through c-Myc-dependent inhibition and alternative splicing of hTERT. J Cell Sci 2002; 115:1305-12.

42 Lin SY, Elledge SJ. Multiple tumor suppressor pathways negatively regulate telomerase. Cell 2003; 113:881-9.

43 Feng XH, Liang YY, Liang M, et al. Direct interaction of c-Myc with Smad2 and Smad3 to inhibit TGF-ßeta-mediated induction of the CDK inhibitor p15(Ink4B). Mol Cell 2002; 9:133-43. 